Unit at the Rutherford Laboratory. This unit was set up in 1971, no doubt on the strength of the decision to ask the government to provide finance for the British high flux beam reactor and since then the unit has been involved in preliminary work on reactor development. Dr Hobbis said on Tuesday that there was no question of his unit, which has a complement of 28 people, being declared redundant but the direction of their work must change. There is a need in Britain, Dr Hobbis said, for such a unit to provide back-up support for neutron beam research and from now on their work would be oriented towards collaboration with Grenoble.

\section{RADIO ASTRONOMY}

\section{West Ford Replayed}

by our Astronomy Correspondent THERE is widespread apprehension in radio astronomy observatories that the launch of a NASA satellite next year may threaten radio observations of the universe. The satellite is the sixth in the series of Applications Technology Satellites (ATS) and is intended as a preliminary to the development of satellites which will broadcast television programmes direct to domestic receivers on the ground.

In spite of this laudable aim-which among other things could lead to the development of an educational broadcasting system for the developing countries--many radio astronomers are regarding the launch of ATS-F with almost the same distaste as they regarded the West Ford project a few years ago. Radio astronomy was then threatened with the possibility of the indiscriminate scattering of metallic needles in Earth orbit. Now radio astronomers fear that the broadcast signal from ATS-F will spill over into one of the bands of the radio spectrum reserved exclusively for radio astronomy. The problem is made more acute because, as one radio astronomer has pointed out, radio observatories can be sited away from the interference produced by large towns and road and rail traffic, but there is no hiding from a geostationary satellite.

Radio astronomers are also concerned over the ATS.F affair because of what some of them regard as a cavalier treatment of the international regulations which govern the allocation of frequencies in the radio spectrum. The radio astronomy band now in danger extends from $2,690 \mathrm{MHz}$ to $2,700 \mathrm{MHz}$, but the International Radio Regulations also ask other users to bear in mind that astronomical observations also extend from $2,690 \mathrm{MHz}$ down to $2,670 \mathrm{MHz}$. Broadcasting satellites have been allocated the band from $2,500 \mathrm{MHz}$ to $2,690 \mathrm{MHz}$, so on paper at least there should be no clash so far as the exclusive radio astronomy band is concerned, but radio astronomers point out that the real picture is more complicated because the broadcasting signal will spill into the radio astronomy band.

The details were spelled out in a report in 1971 to the International Telecommunications Union by its advisory body, the Consultative Committee on International Radio (CCIR). The CCIR report shows that radio observatories require an interfering signal within the $2,690-2,700 \mathrm{MHz}$ band to be less than $-247 \mathrm{dbW} \mathrm{m}^{-2} \mathrm{~Hz}^{-1}$ for a source anywhere in the sky, and very much less if it happens to be close to the astronomical object under observation. But the first proposal to use the broadcasting satellite service would provide a signal spilling into this band at a level of $-232 \mathrm{dbW} \mathrm{m}^{-3} \mathrm{~Hz}^{-1}$, which is more than thirty times the maximum level even under the restricted circumstances that radio astronomers would abandon the part of the sky where the broadcasting satellite is placed.

Both the radio astronomy band and the broadcasting satellite band are, however, equally recognized by the ITU regulations. It seems that most radio astronomers became fully aware of the present threat as recently as last month's meeting of the General Assembly of the Union of International Scientific Radio in Warsaw, when they were told of next year's test of the satellite broadcasting system by ATS.F which will operate at $2,670 \mathrm{MHz}$. It is expected that European observatories will be below the satellite's horizon, but all

\title{
Fischer Acclaimed as Champion
}

BY means of a draw in the 20th game and a win against Spassky in the 21st game, Fischer has reached the coveted total of $12 \frac{1}{2}$ points and consequently becomes the new Chess Champion of the World. The 20th game was fairly quiet since Fischer seemed to be adopting the policy of playing carefully during the latter part of the match, even when playing white. Spassky made some effort to win the end game of rook and two minor pieces each, but the position was always too level for him to make much impression.

The 21st game found Spassky (white in a Sicilian Defence) handling the opening rather listlessly, and it was not long before Fischer gained a slight initiative. Spassky tried to hold on by sacrificing the exchange for two connected passed pawns on the queen's side and the game seemed to be heading for the eighth successive draw of the match when in the diagrammed

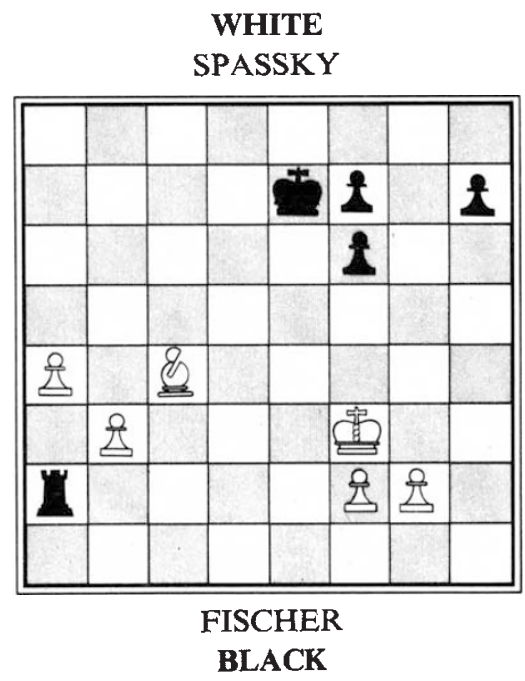

The position after black's 29th move in the 21 st (and last) match game. position he erred by playing in move 30 , P-KN4. This allowed a neat reply by Fischer that established a passed king's rook's pawn for him. Spassky's sealed move $(41, \mathrm{~B}-\mathrm{Q} 7)$ was a further mistake that allowed this pawn a free passage up to the sixth rank rendering any further resistance hopeless, but Spassky obviously realized that even a draw with white was simply not good enough to pull the match out of the fire.

By winning 7 and losing only 2 games played, Fischer has clearly shown his superiority in this match over Spassky. At 29 Fischer has probably reached the peak of his chess-playing ability, combining maximal physical stamina with a single-minded development of his considerable mental prowess for the game. In comparison with previous World Champions he seems to unite the imaginative boldness of Alekhine, the technical mastery of Capablanca and the fighting spirit of Lasker. It is not yet clear that he is quite as deep a strategist as Botvinnik at his best. Nevertheless, he is certainly a very worthy champion and his fluid and attractive style of play seems to have done much to help popularize the game of chess.-J.P.

\begin{tabular}{|c|c|c|c|}
\hline & & & \\
\hline \multicolumn{4}{|c|}{ 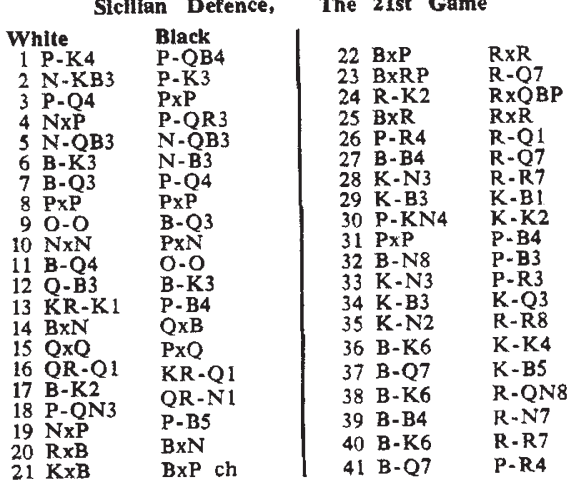 } \\
\hline
\end{tabular}

